\title{
Use of Aspergillus oryzae during sorghum malting to enhance yield and quality of gluten-free lager beers
}

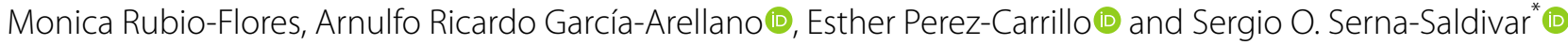

\begin{abstract}
Sorghum has been used for brewing European beers but its malt generally lower beer yields and alcohol contents. The aim of this research was to produce lager beers using worts from sorghum malted with and without Aspergillus oryzae inoculation. Worts adjusted to $15^{\circ}$ Plato from the sorghum malt inoculated with $1 \%$ A. oryzae yielded $21.5 \%$ and $5 \%$ more volume compared to sorghum malt and barley malt worts, respectively. The main fermentable carbohydrate in all worts was maltose. Glucose was present in higher amounts in both sorghum worts compared to barley malt worts. Sorghum-A. oryzae beer had similar specific gravity and alcohol compared to the barley malt beer. Sorghum-A. oryzae beer contained lower amounts of hydrogen sulfide, methanethiol, butanedione, and pentanedione compared to barley malt beer. Sorghum-A. oryzae lager beer had similar yield and alcohol content compared to the barley malt beer but differed in color, key volatiles and aromatic compounds.
\end{abstract}

Keywords: Brewing, Gluten-free, Lager beer, Aspergillus oryzae, Sorghum

\section{Introduction}

Typically, barley has been the most relevant raw material for beer production. Malt production is considered one of the oldest and complex examples of applied enzymology (Gupta et al. 2010). However, the growing interest for gluten-free products and need for efficient cultivars, especially in terms of water usage and drought resistance, have led to consider crops like sorghum. Sorghum is the fifth most important cereal worldwide with an annual production exceeding 57 million tons in 2017 (Food Agriculture Organization 2019). This cereal crop, widely adapted to arid and subtropical ecosystems around the globe, can play a dual role as refined brewing adjuncts or as a source of diastatic malt. For centuries, indigenous sorghum beers, also known as opaque or kaffir, have occupied a prominent place in the diets

\footnotetext{
${ }^{*}$ Correspondence: sserna@tec.mx

Tecnológico de Monterrey, Escuela de Ingeniería y Ciencias, Centro de Biotecnología FEMSA, Ave. Eugenio Garza Sada 2501 Sur, CP 64849 Monterrey, N.L., Mexico
}

of many African people, and the industrialization of this kind of beer started more than 70 years ago (Bogdan and Kordialik-Bogacka 2017; Odibo et al. 2002). The main problems when brewing with sorghum are the lower diastatic power of its malt, especially deficient in $\beta$-amylase activity, and the comparatively higher gelatinization temperature of sorghum starch compared to barley starch (Serna-Saldívar 2010). In a previous research, EspinosaRamírez et al. (2013a, 2013b) successfully produced lager beers from different types of sorghum malts and gluten-free adjuncts, supplemented with $\beta$-amylase or amyloglucosidase.

On the other hand, Aspergillus oryzae, commonly known as Koji, is a fungus important for the production of traditional fermented foods and beverages in Japan and China due to its ability to secrete large amounts of amylolytic, lipolytic and proteolytic enzymes. These features have facilitated the use of A. oryzae in modern biotechnology (Machida et al. 2005; Barbesgaard et al. 1992). In food fermentation, A. oryzae secretes significant amounts of amylases and 
proteases to breakdown complex starches to sugar and proteins to peptides, which are further fermented by yeast and lactic acid bacteria (Kobayashi et al. 2007). Both $A$. oryzae and its enzymes are accepted as constituents of foods (FAO and WHO 1988). A previous study by Heredia-Olea et al. (2017) has analyzed the use of $A$. oryzae with sorghum malt. The research evaluated the use of $A$. oryzae (Koji) as a supplement for sorghum malt to increase the enzyme content of the malt without the direct addition of exogenous enzymes. The results of this study show that the sorghum malt originally inoculated with $1 \%$ of $A$. oryzae improved sorghum malt quality in terms of $\alpha$-amylase and amyloglucosidase activities. Consequently, worts contained higher amounts of Free Amino Nitrogen (FAN) and fermentable carbohydrates. All this, without the generation of waste or additional byproducts that are generated with the addition of purified enzymes, to our knowledge there is no information about the production of lager beers using sorghum malt inoculated with $A$. oryzae. Thus, the main objective of this investigation was to produce and estimate yields of lager beers from optimally malted sorghum with and without $A$. oryzae inoculation and to assess properties of resulting beers in terms of extraction, alcohol content and physicochemical attributes.

\section{Materials and methods Raw materials}

The white sorghum was donated by INIFAP Rio Bravo whereas the A. oryzae 22788 was acquired from the American Type Culture Collection (ATCC). Barley malt for the control mash, hops (Humulus lupus) and fresh lager brewing yeast of the Saccharomyces spp. strain for all experimental treatments were donated by Cuauhtémoc-Moctezuma-Heineken Brewery. Native cornstarch and yellow maize grits with a particle size of 40-60 United States (US) mesh were obtained from Industrias Mexstarch SAPI de CV and Agroindustrias Integradas del Norte SA de CV.

\section{Sorghum characterization}

The thousand-sorghum kernel weight was determined by weighing 100 randomly selected whole kernels (Serna-Saldivar 2012). Test weight was measured with a Winchester Bushel Meter (Seedburo Equipment Company) according to official U.S. grain standard procedures (AACC 2000). Moisture (method 44-15), protein (method 46-13.01), ash (method 08-01) (AACC 2000) and starch (method 996.11) (AOAC 1980) were assayed based on the respective methods.

\section{Oryzae culture}

Aspergillus oryzae was cultured in potato dextrose agar plates at $30{ }^{\circ} \mathrm{C}$ for 5 days. Then, spores were collected and counted in a Neubauer chamber and inoculated into potato dextrose broth and allowed to grow for 5 additional days (Kammoun et al. 2008). Media was centrifuged at $1000 \mathrm{~g}$ for $10 \mathrm{~min}$ in sterile tubes to concentrate mycelium.

\section{Malting process}

For steeping, sorghum grains were mixed with two parts of water $\left(28{ }^{\circ} \mathrm{C}\right)$ containing $0.01 \%$ formaldehyde for $30 \mathrm{~h}$ in a cabinet set at $28{ }^{\circ} \mathrm{C}$. Steeping was conducted under aeration to enhance aerobiosis and respiration. Sorghum samples previously steeped were inoculated with $1 \% \mathrm{w} / \mathrm{w} A$. oryzae mycelium and then placed in plastic trays in a germination cabinet set at $28{ }^{\circ} \mathrm{C}$ with $90 \%$ relative humidity. Moisture losses due to evaporation were controlled by the spraying of water periodically. Samples were collected every $24 \mathrm{~h}$ throughout the $96 \mathrm{~h}$ germination time. Starch (method 996.11) and free amino nitrogen or FAN (method 945.30) were measured daily according to the Association of Official Analytical Collaboration (AOAC) 1980. Malting losses were determined by comparing the weight of the dry malt to the dry weight of the original amount of sorghum kernels. The germinated grains were dehydrated for $24 \mathrm{~h}$ in a forced convection oven set at $50{ }^{\circ} \mathrm{C}$. The malts were coarsely milled using the break rolls of the Chopin mill. Malt losses were obtained using Eq. 1

$$
\text { Malting } \operatorname{loss}(\%)=\frac{\text { Sorghum dry matter }- \text { Malt dry matter }}{\text { Sorghum dry matter }} \text {. }
$$

\section{Mashing procedure}

The grist formulation consisted of $60 \%$ malt (barley, sorghum or sorghum-A. oryzae), $20 \%$ native cornstarch and $20 \%$ maize grits. The brewing adjuncts were mixed with $10 \%$ of the total amount of malt, and then mixed with deionized water in a 1:2.3 ratio. The double mashing was performed according to the procedure of Heredia-Olea et al. (2017). The ${ }^{\circ}$ Plato and volume of resulting wort were measured to calculate the amount of water needed to adjust the wort to $15^{\circ}$ P. The final adjusted volume was recorded as wort yield. Cascade hop pellets were added to the sweet wort adjusted to $15^{\circ}$ Plato in a rate of $0.35 \mathrm{~g} / \mathrm{L}$. In a vessel, $90 \%$ of the hops were added to the sweet wort before heating to boiling for $50 \mathrm{~min}$. The $10 \%$ remaining hops were added $10 \mathrm{~min}$ before discontinuing heat. The hopped wort was centrifuged at $1800 \mathrm{~g}$ for 10 min to remove the spent hops and trub solids by 
decantation. The resulting hopped worts were readjusted with sterile water to $15^{\circ} \mathrm{P}$.

\section{Fermentation}

Prior to the wort inoculation, the percent of yeast solids was determined using a Spin-Down Method (Bendiak 1997). The sample was homogenized by placing the yeast in a glass with agitation for $30 \mathrm{~min}$ to remove gas bubbles. The glass containing the sample was maintained in contact with iced water during the preparation. A yeast cell counter Nucleocounter ${ }^{\circledR}$ YC-100TM (Chemometec) was used to measure the total cell count and viability of cells in suspension. The system uses a cassette pre-coated with propidium iodide dye, which stains the cells' nuclei and is then measured by an automatic fluorescence microscope. This method was carried out before introducing the yeast to the fermentation tanks and after the yeast removal. For a lager analysis, the parameter of the Nucleocounter ${ }^{\circledR}$ YC-100TM was set to diploid. Worts from three different malt treatments were obtained from previously malted sorghum, barley and sorghum- $A$. oryzae. The wort placed in sterilized liter jugs was poured into a 6-L flask inside a microbiological hood furnished with a gasfired Bunsen burner to prevent cross-contamination. A previously sterilized oxygenator was introduced to the wort, transferring oxygen through a sterilized tube from a valve. The oxygenation time was set to $5 \mathrm{~min}$. Inside the sterilized area, the oxygenated wort was then transferred to a sterilized 3-L fermentation laboratory-scale bioreactor $\left(\right.$ Applikon $\left.{ }^{\circledR}\right)$. Once the wort temperature reached $12{ }^{\circ} \mathrm{C}$ the yeast was pitched to the tank using a sterile pipette. Yeast was added at a rate of $10 \mathrm{~mL} / \mathrm{L}$ wort equivalent to $6 \times 10^{6}$ yeast cells $/ \mathrm{mL}$. The $\mathrm{pH}$ of wort and beer was determined using a potentiometer sensor installed in the fermentation tank. Measurements were taken every minute during the programmed $120 \mathrm{~h}$ fermentation. The lager fermentation lasted $120 \mathrm{~h}$. The first $24 \mathrm{~h}$ was set at $12{ }^{\circ} \mathrm{C}$ and afterward at $15{ }^{\circ} \mathrm{C}$ for the remaining time. Samples were collected at 0,12, 24, 48 and $120 \mathrm{~h}$ for analyses. After $120 \mathrm{~h}$ of fermentation, the maturation procedure took place. The temperature of the bioreactors was set at $2{ }^{\circ} \mathrm{C}$ for $24 \mathrm{~h}$. After the maturation step, the yeast sediment was removed from the fermentation tanks by opening the lower valve located in the cone structure. The yeast was recollected in a flask for further viability analysis. Once all of the yeast was removed, the beer was drained from the fermentation tanks into flasks for further yeast filtration. The remaining yeast was precipitated by centrifugation at $1800 \mathrm{~g}$ during $10 \mathrm{~min}$ and the beer by decantation.

The total volume of the filtered beer was measured using a graduated cylinder. The filtered beer was stored in sterile glass jugs at $2{ }^{\circ} \mathrm{C}$ with minimal headspace to prevent oxidation and deterioration until further analysis.

\section{Analytical assays}

Sorghum grain germination capacity was determined according to Serna-Saldivar (2012). In brief, a representative sample of 100 caryopses was taken randomly and soaked in excess water for $30 \mathrm{~h}$ with aeration. Then, the soaked kernels were placed on Petri dishes with soaked filter paper for controlled germination for 3 days in a cabinet set at $28^{\circ} \mathrm{C}$. Germinated kernels were considered those that developed rootlets and/or acospires (plumulae). Values were expressed on percentage. Starch was measured according to the colorimetric Method 996.11 of the AOAC (1980) whereas FAN of wort and beer by the spectrophotometry methods 8.10 and 9.10 (EBC 2008) based on the ninhydrin reaction. Specific gravity was determined at $20{ }^{\circ} \mathrm{C}$ with a digital density meter of the oscillation type using standard method 8.2.2 for worts and 9.43.2 for beers (EBC 2008). The extracts of worts were determined with a density meter following method 8.3 (EBC 2008). In beers, the calculations of original, real and apparent extracts were based on the original and specific gravity determinations following the method 9.4 (EBC 2008). Color of hopped wort was measured by spectrophotometry according to the European Brewery Convention (EBC) and $\mathrm{pH}$ with a potentiometer previously calibrated with 4.0 and $7.0 \mathrm{pH}$ buffers (EBC 2008). The yield was determined by measuring of wort volume ( $15^{\circ}$ Brix) obtained per kilogram of dry materials (Cortes-Ceballos et al. 2015). Spent grains and solids lost after centrifugation were determined gravimetrically.

The contents of fermentable carbohydrates fructose, glucose, disaccharides and trisaccharides were determined using a High-Performance Liquid Chromatograph (HPLC) equipped with a Refractive Index detector following the method 8.7 for worts and 9.27 for beers (EBC 2008). The ethanol in beer was determined using the Near Infrared Spectroscopy (NIR) rapid method EBC 9.2.6 (2008). The determination of lower boiling point volatile compounds in beer (alcohols, esters, acetaldehyde, and dimethyl sulfide) was measured by automatic headspace gas chromatography (method 9.39 of the EBC 2008) equipped with a chemically bonded fused silica capillary column and flame ionization detector. Volatile compounds were determined comparing with authentic international standards. Colors of worts and beers were determined according to methods 8.5 and 9.6, respectively (EBC 2008). The measurement of volatile sulfur compounds in beer was determined by Gas Chromatography equipped with a Sulfur Chemiluminescence Detector (ASBC 1994 Method Beer-44). The determination of vicinal diketones (VKD), 2,3-butanedione (diacetyl), 
2,3-pentanedione and their precursors in beers was measured by gas chromatography coupled with an electron capture detector following the headspace method 9.24.2 (EBC 2008).

\section{Statistical analysis}

The Minitab 16 statistical software (Minitab, State College, PA, U.S.A.) was employed to identify statistically significant differences among treatments and compare means with Tukey tests $(\mathrm{P} \leq 0.05)$.

\section{Results}

\section{Sorghum characterization}

The white sorghum had a thousand-kernel weight of $24.42 \pm 0.49 \mathrm{~g}$, apparent bulk density of $79.09 \pm 2.75 \mathrm{~kg} /$ $\mathrm{HL}$ and a subjective endosperm texture of $2.12 \pm 0.37$ $(1=$ totally corneous or vitreous, $2.5=$ intermediate endosperm texture and $5=$ totally floury or chalky). In terms of chemical composition, the sorghum contained $10.07 \pm 0.03 \%$ moisture, $9.73 \pm 0.05 \%$ protein, $69.27 \pm 0.52 \%$ starch, $5.09 \pm 0.16 \%$ crude fiber and $2.03 \pm 0.13 \%$ ash expressed on a dry matter basis. The physical and chemical properties fall within expected values for this cereal grain (Serna-Saldivar and EspinosaRamirez 2018; Serna-Saldivar 2010).

\section{Malting process}

The addition of $1 \%(\mathrm{w} / \mathrm{w})$ A. oryzae mycelium to sorghum kernels before malting did not affect the sorghum germination capacity, $98.33 \pm 1.03 \%$ vs $98.75 \% \pm 1.98 \%$ for the control sorghum malt. After 4 days of germination, the regular and sorghum $-A$. oryzae malts lost $9.9 \%$ and $14.8 \%$ of their dry matter, respectively. The granulation of particle size distribution is critically important because it affects lautering or filtration rate and the availability of malt reserve components to enzymes during mashing. Table 1 compares the particle size distributions of the three malts. There was a significant difference between the barley malt and both sorghum malts especially in terms of particles retained by the biggest sieve (US mesh No 20). This large sieve retained most of the glumes or husks of the barley malt. This is because the sorghum kernel is considered a naked caryopsis where the glumes usually detach during harvesting. A distinguished difference can also be noted between the barley malt and both the sorghum malts in the smallest mash $(-100)$. This difference can be attributed to the difference in endosperm texture, which was harder for sorghum. The barley malt normally has a floury and friable endosperm, which is more prone to milling and therefore generate fine particles composed mostly of starch granules that pass the 100 mesh sieve. The barley malt contained less FAN (1.088 mg/g malt) compared to the sorghum malts.
Table 1 Particle size distributions of malts ground using a Chopin roller mill

\begin{tabular}{lrrr}
\hline US mesh sieve\# & Barley malt & Sorghum malt & $\begin{array}{l}\text { Sorghum } \\
\text { and } A . \text { oryzae } \\
\text { malt }\end{array}$ \\
\hline 20 & $8.80 \pm 0.11^{\mathrm{A}}$ & $4.32 \pm 0.29^{\mathrm{B}}$ & $4.39 \pm 0.14^{\mathrm{B}}$ \\
40 & $29.89 \pm 0.58^{\mathrm{B}}$ & $36.42 \pm 1.27^{\mathrm{A}}$ & $30.10 \pm 0.40^{\mathrm{B}}$ \\
70 & $30.63 \pm 0.35^{\mathrm{B}}$ & $45.00 \pm 1.28^{\mathrm{A}}$ & $28.25 \pm 0.60^{\mathrm{B}}$ \\
80 & $8.07 \pm 0.52^{\mathrm{C}}$ & $10.85 \pm 0.28^{\mathrm{B}}$ & $27.34 \pm 0.32^{\mathrm{A}}$ \\
100 & $2.15 \pm 0.11^{\mathrm{B}}$ & $0.83 \pm 1.88^{\mathrm{C}}$ & $3.54 \pm 0.38^{\mathrm{A}}$ \\
-100 & $20.59 \pm 0.49^{\mathrm{A}}$ & $1.42 \pm 0.23^{\mathrm{C}}$ & $6.43 \pm 0.23^{\mathrm{B}}$ \\
\hline
\end{tabular}

All data are expressed has percentage in weight

Means comparisons with different letter(s) within rows are statistically different $(P<0.05)$

Figure 1 shows the assayable starch and FAN contents of malts during germination. At the same day of malting, there were not differences between starch contents. Total starch content gradually diminished throughout germination in both treatments. The highest starch change was observed after the first $24 \mathrm{~h}$ of germination with a reduction of 4 units. The starch content of malts germinated for $96 \mathrm{~h}$ decreased 5 and 6 units in regular sorghum and sorghum $-A$. oryzae malts, respectively. The FAN values between malts were about the same between the original grains and malts germinated for only $24 \mathrm{~h}$. However, the FAN contents greatly increased when malts were germinated for more than $48 \mathrm{~h}$. FAN values gradually increased with germination time so the regular sorghum and sorghum- $A$. oryzae malts germinated for $96 \mathrm{~h}$ contained at least 6 and 8 times more FAN compared to the unmalted sorghum kernels. The higher FAN content of the sorghum $-A$ oryzae malt is attributed to the presence of additional exogenous proteolytic enzymes synthesized by the mold.

\section{Wort properties}

Table 2 data show that the worts obtained after the double mashing, lautering and the hop boil processes were within the specific gravity and dissolved solid contents expected for lager beers (Gialleli et al. 2017). The volume of $15^{\circ}$ Plato wort was used as an indicator to quantify differences in wort yields from the various malts. The barley and sorghum worts yielded lower wort volumes compared to the wort obtained from the grist containing the sorghum $-A$. oryzae malt (Table 2 ). The regular sorghum malt yielded $17.2 \%$ less volume compared to the barley malt. Interestingly, the sorghum- $A$. oryzae treatment yielded $6.5 \%$ more wort volume and $27.6 \%$ compared with worts produced by the barley malt and sorghum malt, respectively. This relevant finding indicates that the proposed strategy to enhance enzymatic activity of the 

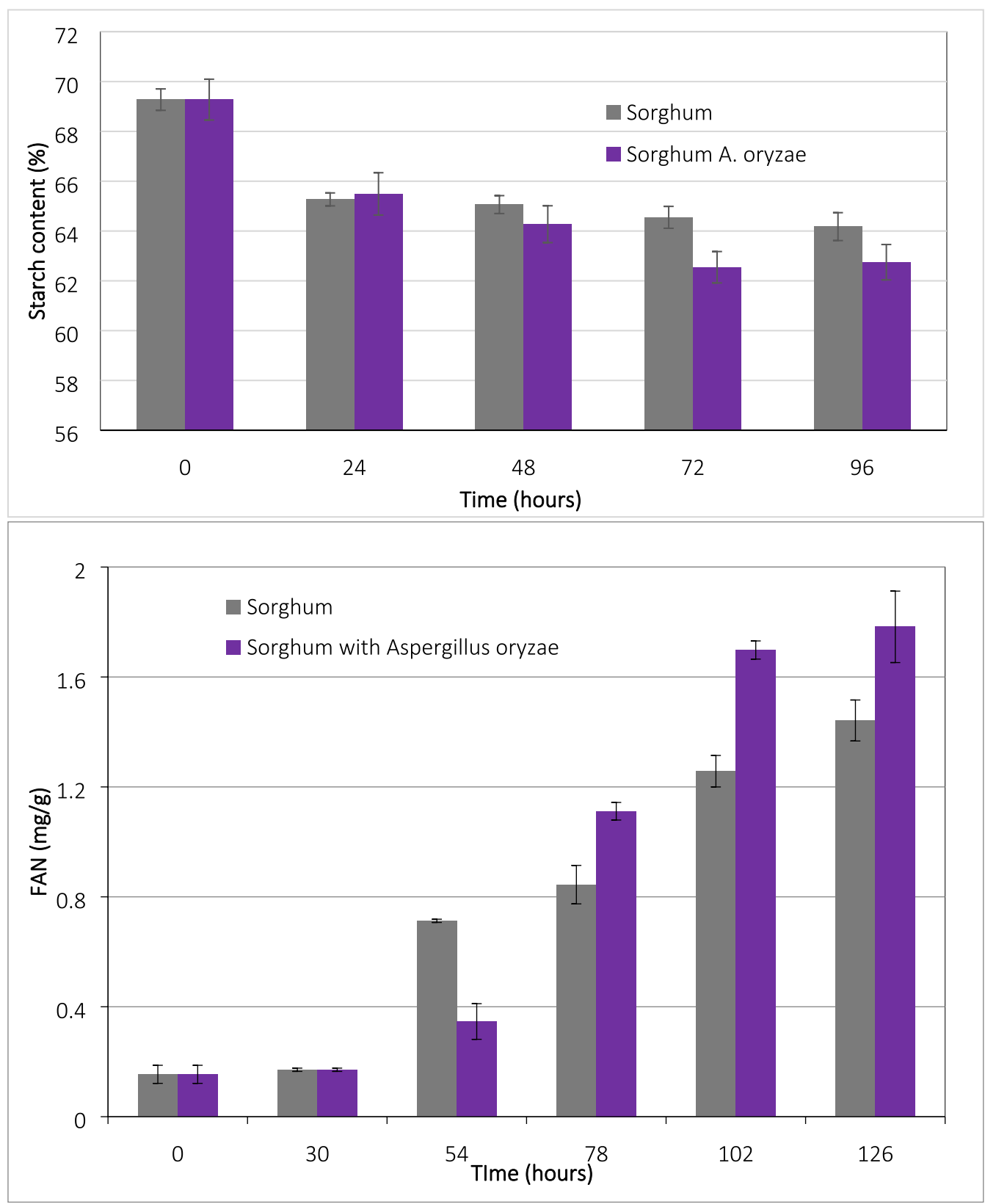

Fig. 1 Changes in starch (dry basis) and Free Amino Nitrogen (mg/g) contents during germination of sorghum with or without A. oryzae

sorghum malt was effective and promising for the production of gluten-free beers. The amount of dry brewers spent grains obtained after lautering and centrifugation indicated that the regular sorghum yielded the highest amounts (Table 2). The amounts of spent grains generated by the barley malt and sorghum- $A$. oryzae malt were approximately 25 and $35 \%$ less compared to the regular sorghum. In terms of specific gravity, $\mathrm{pH}$, original extract and fructose and maltotriose contents, there were not differences among the three worts. In all worts, maltose was the most abundant fermentable sugar followed by glucose. However, the malt treatment affected maltose and glucose concentrations in worts. The regular sorghum and barley worts contained the highest and lowest glucose values (Table 2). In case of maltose concentrations, the wort from barley contained approximately $35 \%$ and $29 \%$ more maltose compared to the regular sorghum and sorghum $-A$. oryzae worts, respectively. The wort produced from sorghum-A.oryzae malt contained 21.7 and $6.8 \%$ more FAN concentrations compared to 
Table 2 Quality parameters, yields and carbohydrates profiles of worts ( $15^{\circ}$ Plato) produced using malts form barley, and sorghum without or with A. oryzae

\begin{tabular}{|c|c|c|c|}
\hline & Wort from barley malt & Wort from sorghum malt & $\begin{array}{l}\text { Wort from sorghum } \\
\text { with } A \text {. oryzae malt }\end{array}$ \\
\hline Yield (15º Plato) (L/kg) & $4.02 \pm 0.03^{B}$ & $3.33 \pm 0.05^{C}$ & $4.25 \pm 0.04^{\mathrm{A}}$ \\
\hline Dry Brewer's spent grains after lautering (g solids/kg grist) & $151 \pm 3.20^{B}$ & $175.92 \pm 2.62^{\mathrm{A}}$ & $181.3 \pm 0.27^{\mathrm{A}}$ \\
\hline Solids lost after wort centrifugation (g solids/kg grist) & $148 \pm 3.00^{B}$ & $225 \pm 4.21^{\mathrm{A}}$ & $81 \pm 1.70^{c}$ \\
\hline Specific gravity @ 20ㄷ & $1.061 \pm 0.01$ & $1.061 \pm 0.01$ & $1.061 \pm 0.01$ \\
\hline $\mathrm{pH} @ 20^{\circ} \mathrm{C}$ & $5.81 \pm 0.08$ & $5.50 \pm 0.16$ & $5.73 \pm 0.13$ \\
\hline Original extract (\%) & 15 & 15 & 15 \\
\hline \multicolumn{4}{|l|}{ Carbohydrates } \\
\hline Fructose $(\% w / w)$ & $0.039 \pm 0.001$ & $0.037 \pm 0.001$ & $0.036 \pm 0.001$ \\
\hline Glucose (\%w/w) & $1.895 \pm 0.005^{C}$ & $4.379 \pm 0.011^{\mathrm{A}}$ & $3.772 \pm 0.009^{B}$ \\
\hline Maltose $(\% \mathrm{w} / \mathrm{w})$ & $7.661 \pm 0.039^{A}$ & $5.009 \pm 0.022^{C}$ & $5.435 \pm 0.028^{B}$ \\
\hline Maltotriose (\%w/w) & $1.456 \pm 0.012^{B}$ & $1.564 \pm 0.013^{\mathrm{A}}$ & $1.479 \pm 0.009^{B}$ \\
\hline Total fermentable sugars (\%w/w) & 11.051 & 10.989 & 10.724 \\
\hline Free amino nitrogen (mg/L) & $173.9 \pm 4.35^{\mathrm{C}}$ & $206.5 \pm 6.64^{\mathrm{B}}$ & $221.1 \pm 5.27^{\mathrm{A}}$ \\
\hline Color $\left({ }^{\circ} \mathrm{EBC}\right)$ & $8.65 \pm 0.012^{A}$ & $4.62 \pm 0.012^{B}$ & $4.11 \pm 0.012^{c}$ \\
\hline
\end{tabular}

Mean comparisons with different letter(s) within rows are statistically different $(P<0.05)$

the barley and regular sorghum worts. The color of worts (Table 2) was significantly affected by the sort of malt. Compared to the barley malt wort, both sorghum worts showed almost twofold color values.

\section{Fermentation analyses}

There were not differences between treatments in terms of yeast in suspension $(10.55 \pm 0.33 \%)$ and dead cells $(1.89 \pm 0.21 \%)$. Figure 2 depicts changes of fermentable sugars during $120 \mathrm{~h}$ fermentation of the different worts. The charts display that glucose and fructose were totally consumed after $50 \mathrm{~h}$. On the other hand, maltose and maltotriose were gradually utilized throughout the whole fermentation process. Maltose was totally fermented in all worts after $120 \mathrm{~h}$ of fermentation whereas small amounts of maltotriose remained in the barley and sorghum- $A$. oryzae worts. For fructose, an increment in its concentration was visualized after $15 \mathrm{~h}$ of fermentation.

There were not differences between $\mathrm{pH}$, FAN, superior alcohols, acetaldehyde, ethyl acetate, isoamyl acetate, dimethylsulfide and S-methyl acetate among treatments (Table 3). As expected there were close relationships among beer specific gravity, attenuation and ethanol concentrations (Table 3). The regular sorghum beer specific gravity was about $0.49 \%$ higher compared to the barley malt and $A$. oryzeae-sorghum beers. The observed differences are attributed to the almost $11 \%$ higher ethanol concentrations observed in the barley and A. oryzae-sorghum beers. As a result, the apparent and true attenuation values of the regular sorghum treatment were about $11.5 \%$ and $7 \%$ lower compared to the barley beer and sorghum $-A$. oryzae beers, respectively (Table 3 ). Interestingly, the beer produced with sorghum contained $37 \%$ less ethyl hexanoate compared to the counterpart produced with barley malt. In terms of sulfur compounds, hydrogen sulfide content was highest for the barley beer and lowest for the sorghum-A. oryzae beer. On the other hand, methanethiol content was comparatively higher for barley malt beer than the sorghum-A. oryzae beer. Large differences between the concentration of VKD compounds 2,3 butanedione and 2,3 pentanedione were observed when both sorghum beers were compared with the barley beer. The amounts of these compounds were approximately $10 \%$ of the concentrations assayed in the barley malt beer (Table 2). Likewise, the EBC color of the barley beer was significantly higher compared to the two experimental sorghum beers.

\section{Discussion \\ Malt properties}

The main chemical changes that grains undergo during malting are the reduction in assayable starch and hemicellulose contents. During this physiological process, the cell bound components weaken due to the synthesis of degrading enzymes like cellulases and arabinoxylanases. The hydrolyzed cell walls allow the entry of other relevant enzymes that will degrade protein bodies and matrix and starch granules (Boulton and Quain 2001). There are many investigations which clearly conclude that malted sorghum has significantly lower diastatic activity compared to barley malt especially in terms of maltose-producing $\beta$-amylase. These deficiencies have 

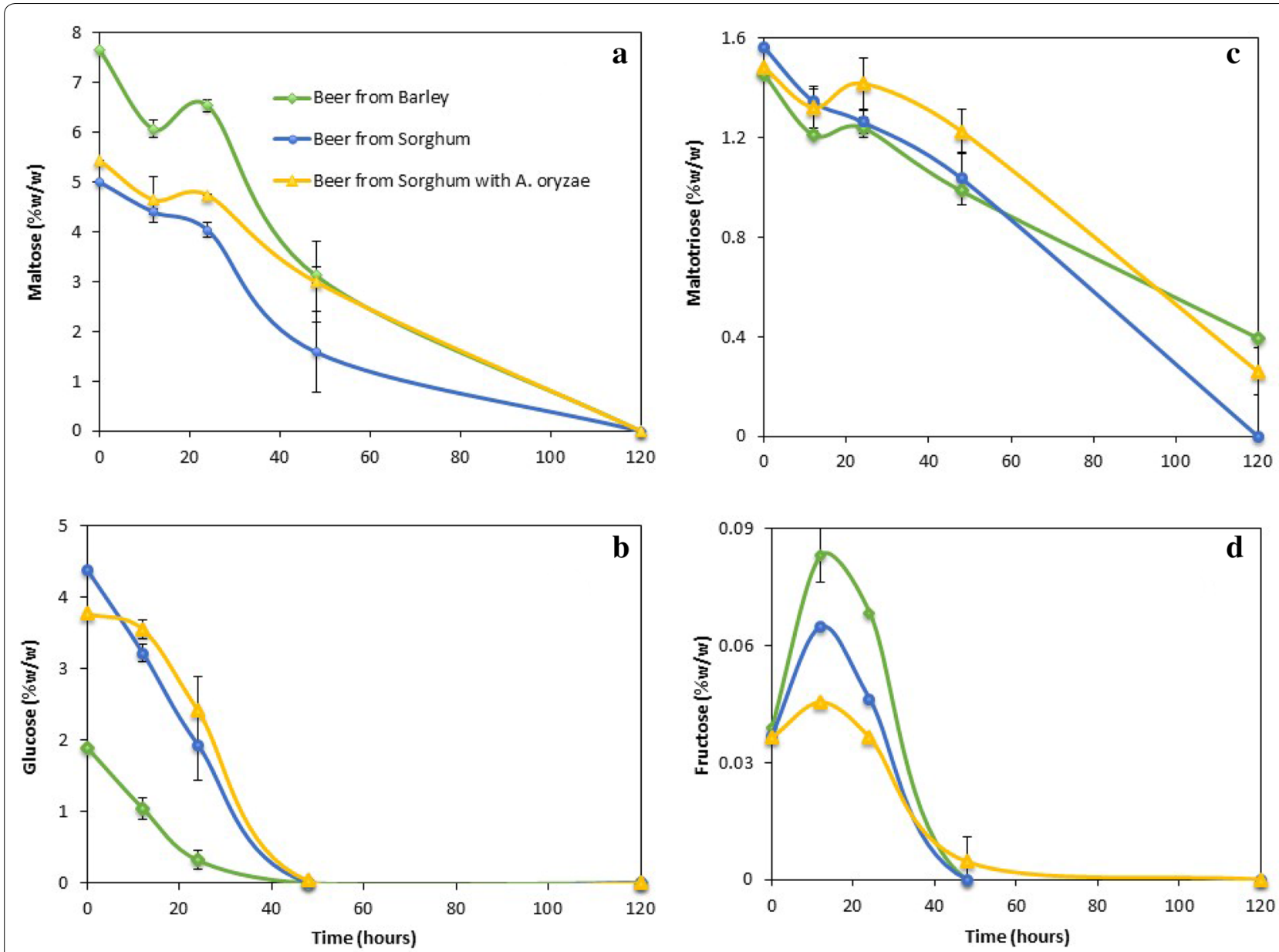

Fig. 2 Fermentable sugar depletion in worts from barley, sorghum or sorghum with A. oryzae fermented during 120 h. a Maltose (\%); b glucose (\%); c maltotriose (\%); d fructose (\%)

been counteracted by the addition of exogenous enzymes like $\alpha$ and $\beta$-amylases, glucoamylase or amyloglucosidase and even proteolytic enzymes that improve the exposure of the starch granules to amylolytic enzymes (Serna-Saldivar and Rubio-Flores 2016). The idea of inoculating $A$. oryzae during the malting process of sorghum is based in the fact that this mold synthesizes relevant enzymes like amylases and proteases that enhance the conversion of starch and proteins into fermentable carbohydrates and simpler and soluble nitrogenous compounds, respectively. Heredia-Olea et al. (2017) observed that $\alpha$-amylase activity of sorghum malt was positively affected by addition of $A$. oryzae but it did not affect $\beta$-amylase activity. The conversion of starch into linear and branched dextrins explains the significant reduction of starch content during germination. In addition, the proteases generated are distributed to the entire caryopsis and hydrolyze conjugated proteins associated with amylases in order to activate starch-degrading enzymes. The proteases also degrade germ and endosperm proteins, solubilizing approximately $30 \%$ of the total protein. The sorghum malt contained higher amounts of readily assimilable amino acids (FAN) compared to the barley malt and other cereals such as wheat (Hill and Stewart 2019) likely enhancing yeast nutrition during beer fermentation and production of relevant fusel alcohols.

\section{Wort properties}

The regular sorghum malt generated less $15^{\circ} \mathrm{P}$ wort yield compared to the barley malt (Table 2). Similar difference was reported by Espinosa-Ramírez et al. (2013a) who observed that barley malt yielded was up to $24 \%$ more $12{ }^{\circ} \mathrm{P}$ wort and similar FAN and $\mathrm{pH}$ values compared with their counterparts produced with white or red sorghum malts. According to Espinosa-Ramírez et al. (2014) and Heredia-Olea et al. (2017), the use of regular sorghum malt usually yields worts with lesser amounts of fermentable carbohydrates and FAN contents and their 
Table 3 Composition and characteristics of beers from barley, and sorghum without or with $A$. oryzae

\begin{tabular}{|c|c|c|c|}
\hline & Beer from Barley malt & Beer from Sorghum malt & $\begin{array}{l}\text { Beer from Sorghum } \\
\text { with A. oryzae Malt }\end{array}$ \\
\hline Specific gravity@ $20^{\circ} \mathrm{C}$ & $1.016 \pm 0.01^{\mathrm{B}}$ & $1.021 \pm 0.01^{\mathrm{A}}$ & $1.019 \pm 0.01^{\mathrm{AB}}$ \\
\hline $\mathrm{pH}$ & $4.08 \pm 0.05^{\mathrm{A}}$ & $3.96 \pm 0.22^{\mathrm{A}}$ & $4.00 \pm 0.12^{\mathrm{A}}$ \\
\hline Apparent attenuation (\%) & $72.76 \pm 0.09^{A}$ & $64.35 \pm 0.01^{B}$ & $68.05 \pm 0.01^{B}$ \\
\hline Real attenuation (\%) & $60.09 \pm 0.01^{\mathrm{A}}$ & $53.33 \pm 0.12^{\mathrm{B}}$ & $55.66 \pm 0.01^{A B}$ \\
\hline Ethanol (\%v/v) & $5.25 \pm 0.07^{A}$ & $4.68 \pm 0.05^{\mathrm{B}}$ & $5.28 \pm 0.02^{A}$ \\
\hline FAN (mg/Lt) & $56.18 \pm 3.45^{\mathrm{A}}$ & $59.72 \pm 6.13^{A}$ & $66.23 \pm 3.64^{\mathrm{A}}$ \\
\hline \multicolumn{4}{|l|}{ Superior alcohols } \\
\hline Propanol (ppm) & $13.78 \pm 0.01^{\mathrm{A}}$ & $14.40 \pm 2.02^{\mathrm{A}}$ & $16.31 \pm 0.45^{A}$ \\
\hline Isobutanol (ppm) & $13.14 \pm 0.20^{\mathrm{A}}$ & $18.52 \pm 8.77^{\mathrm{A}}$ & $15.21 \pm 0.45^{\mathrm{A}}$ \\
\hline Isoamyl alcohol (ppm) & $85.55 \pm 1.86^{\mathrm{A}}$ & $86.34 \pm 9.10^{\mathrm{A}}$ & $99.16 \pm 1.22^{\mathrm{A}}$ \\
\hline \multicolumn{4}{|c|}{ Volatile and ester compounds } \\
\hline Acetaldehyde (ppm) & $3.13 \pm 0.69^{A}$ & $2.87 \pm 0.52^{\mathrm{A}}$ & $1.92 \pm 0.51^{\mathrm{A}}$ \\
\hline Ethyl acetate (ppm) & $13.24 \pm 0.20^{\mathrm{A}}$ & $7.78 \pm 1.70^{\mathrm{A}}$ & $14.84 \pm 2.39^{\mathrm{A}}$ \\
\hline Isoamyl acetate (ppm) & $0.977 \pm 0.001^{\mathrm{A}}$ & $0.648 \pm 0.130^{A}$ & $1.28 \pm 0.25^{\mathrm{A}}$ \\
\hline Ethyl hexanoate (ppm) & $0.068 \pm 0.001^{\mathrm{A}}$ & $0.046 \pm 0.040^{B}$ & $0.059 \pm 0.010^{\mathrm{AB}}$ \\
\hline \multicolumn{4}{|l|}{ Sulfur compounds } \\
\hline Hydrogen sulfide (ppb) & $26.77 \pm 0.69^{A}$ & $19.63 \pm 1.88^{B}$ & $3.61 \pm 0.19^{C}$ \\
\hline Methanethiol (ppb) & $3.13 \pm 0.13^{\mathrm{A}}$ & $2.18 \pm 0.45^{\mathrm{AB}}$ & $1.73 \pm 0.01^{B}$ \\
\hline Dimethylsulfide (ppb) & $43.09 \pm 8.29^{A}$ & $63.94 \pm 10.93^{A}$ & $62.44 \pm 0.96^{A}$ \\
\hline S-methyl acetate (ppb) & $24.87 \pm 1.45^{\mathrm{A}}$ & $18.01 \pm 5.04^{\mathrm{A}}$ & $16.17 \pm 0.51^{\mathrm{A}}$ \\
\hline \multicolumn{4}{|l|}{ VDK compounds } \\
\hline 2,3 Butanedione (ppm) & $0.440 \pm 0.050^{\mathrm{A}}$ & $0.041 \pm 0.020^{B}$ & $0.018 \pm 0.010^{B}$ \\
\hline 2,3 Pentanedione (ppm) & $0.240 \pm 0.020^{A}$ & $0.033 \pm 0.020^{B}$ & $0.008 \pm 0.010^{B}$ \\
\hline \multicolumn{4}{|l|}{ Color } \\
\hline Color ( $\left.{ }^{\circ} \mathrm{EBC}\right)$ & $6.36 \pm 0.09^{A}$ & $2.91 \pm 0.29^{B}$ & $3.37 \pm 0.14^{\mathrm{B}}$ \\
\hline
\end{tabular}

Mean comparisons with different letter(s) within rows are statistically different $(P<0.05)$

fermented beers with lower alcohol contents. These differences, especially in terms of generation of maltose and glucose, may be attributed to the higher $\beta$-amylase and amyloglucosidase activities of the barley and sorghum- $A$. oryzae malts. It is well known that malt and adjunct starches are hydrolyzed to dextrins and sugars during mashing (Serna-Saldivar and Espinosa-Ramirez 2018). In terms of the preferred carbon source, Carlsen and Nielsen (2001) studied the influence of maltose and maltodextrins differing in chain length, glucose, fructose, galactose, sucrose, glycerol, mannitol and acetate on $\alpha$-amylase production by $A$. oryzae. Productivity was found to be higher during growth on maltose and maltodextrins, which are present in relatively high amounts in typical worts. Maltose was the most abundant carbohydrate in the control and experimental worts (Table 2). This is due to the concerted enzymatic action of $\alpha$ - and $\beta$-amylases. The sorghum worts contained more glucose and less maltose than the barley wort. This is related to the higher $\beta$-amylase activity reported in the barley malt. Even though the worts were adjusted to $15^{\circ}$ Plato, the total amount of fermentable sugars did not total 15\% due to the presence of dextrins. Dextrins commonly account for $90 \%$ of the residual carbohydrate of beer because regular yeast is not capable of fermenting these carbohydrates. Approximately, $40-50 \%$ of the dextrins are oligosaccharides containing 4-9 glucose units, and the remaining $50-60 \%$ are higher dextrins with 10 or more glucose units (Boulton and Quain 2001). EspinosaRamírez et al. (2013a) enhanced the amounts of fermentable sugars in the sorghum malt worts with the addition of $\beta$-amylase. When amyloglucosidase was added, the total sugar content increased $20 \%$ and consequently the glucose content was five times higher compared with worts without exogenous enzymes. It is well known that $A$. oryzae is a mold that synthesizes large amounts of amylolytic, proteolytic and lipolytic enzymes. In fact, commercial mold cultures are used to produce and isolate enzymes widely used by the food industries. The main disadvantage of sorghum malt is its relatively low production of $\beta$-amylase, key enzyme in brewing operations because it complements the activity of $\alpha$-amylase. 
Furthermore, the color of the beer is influenced by Maillard reactions that occur between sugars and amino-compounds (including the amino acids) during the hop-boil step, which gave rise to colored and flavored substances. The proportions of the flavored fermentation products made by yeast are dependent on the nitrogenous substances that are present. Nitrogenous components are present in the form of amino acids, small peptides, and proteins. Recommended FAN concentrations of wort range from 150 to $200 \mathrm{mg} / \mathrm{L}$ (Boulton and Quain 2001). Table 1 clearly depicts that the barley wort contained slightly lower FAN values compared to the sorghum with and without $A$. oryzae counterparts. In fact, the sorghum wort with $A$. oryzae contained $27 \%$ more FAN compared to the control barley counterpart. The significant difference is attributed to the synthesis and action of proteases (mainly carboxypeptidases) produced by the Aspergillus. Malt carboxypeptidases have optimum activity at temperatures between 40 and $60{ }^{\circ} \mathrm{C}$ and are inactivated at $70{ }^{\circ} \mathrm{C}$. Likely the double mashing process gave these enzymes the opportunity to hydrolyze proteins into FAN components (Boulton and Quain 2001). The proteases generated by the mold facilitated the entrance of amylases associated to the sorghum malt and $A$. oryzae. This mold is known to express high amounts of amyloglucosidases that convert linear and branched dextrins into glucose (Heredia-Olea et al., 2017). The hydrolyzed peptides are converted to higher alcohols during fermentation (Barredo-Moguel et al. 2001). Briggs et al. (2004) indicate that 100 to $140 \mathrm{mg} / \mathrm{L}$ is regarded as the minimum level of FAN needed for trouble-free fermentations. The soluble proteins and polypeptides that remain in the fermented wort contribute to the 'body' and 'mouth-feel' of the beer, its foaming properties, and its susceptibility to haze formation.

\section{Fermentation and beer parameters}

Glucose and fructose consumption profiles during fermentation followed the expected trend. According to Cason et al. (1987), glucose and fructose are taken up by the same membrane transport system which explains the similar consumption profiles. The maltose consumption profiles were the same for all treatments. Cason et al. (1987) observed that utilization rates of maltose were identical independently of the adjunct concentration. The rapid consumption of glucose and fructose exerted catabolite repression on the maltose membrane transport system or any of the subsequent metabolic steps of maltose catabolism to glucose. Therefore, maltose started to be utilized when glucose or fructose levels fall to a cut-off point below which catabolite repression did not occur (Cason et al. 1987). The metabolism of maltose and maltotriose is highly interconnected. Both sugars are $\alpha$-glucosides transported by the activated $\alpha$-glucoside-Hc symporter encoded by gen AGT1. This permease, which is maltose inducible, has the same affinity for maltose and maltotriose (Zastrow et al. 2000). These authors observed a single exponential growth phase of maltotriose fermented by Saccharomyces cereviseae grown in medium containing glucose, maltose or maltotriose as carbon and energy sources indicating that the metabolism of this particular fermentable sugar was oxidative. In terms of sugar consumption, fermented beers for the three malt treatments did not show any significant differences.

Final specific gravity value in beer is closely related to the final ethanol content (Esslinger 2009) and this relationship was observed in all beers. In case of attenuation, the values obtained herein were lower compared to the ones reported by Esslinger (2009) for regular barley and sorghum beers where a final attenuation of $82.1 \%$ and $79.7 \%$ was observed, respectively. In terms of beer specific gravity, $\mathrm{pH}$, ethanol, and FAN contents, the use of sorghum-A. oryzae improved values compared to the use of only sorghum malt and similar to the barley malt beer. Espinosa-Ramírez et al. (2014) obtained similar ethanol contents when barley malt beers were compared with sorghum malt beers produced with exogenous amyloglucosidase. The superior alcohols' yeast metabolism was not affected by the malt treatment despite dissimilarities in FAN concentrations. Esters are the products of the enzymatic catalysis of organic acids, ethanol and higher alcohols. Their formation is closely related to yeast propagation and lipid metabolism (Pires et al. 2014). Beer contains more than 50 different esters, from which three are of higher relevance because they greatly affect beer flavor: ethyl acetate, iso-amyl acetate, iso-butyl acetate. Since the sorghum $-A$. oryzae treatment had sixfold and fourfold less hydrogen sulfide than barley beer and sorghum beer, respectively, the difference can be attributed to its higher rate of catabolism mediated by the mold. In terms of hydrogen sulfide production, all beer treatments were statistically different, where only the sorghumA. oryzae beer was under the threshold level of $5 \mathrm{ppb}$. It arises through yeast autolysis at the end of fermentation or during maturation. The best understood carbonyl flavor compounds associated with yeast fermentation are the VKD, which include diacetyl and 2,3 pentanedione. This led to high levels of VKD, during fermentation owing to effects on the regulation of valine synthesis by the yeast. According to Esslinger (2009) the beer taste thresholds of diacetyl and 2,3 pentanedione range from 0.08 to $0.2 \mathrm{ppm}$ and from 0.5 to $0.6 \mathrm{ppm}$. Beer from barley contained significantly higher levels of both butanedione and 2,3 pentanedione whereas beer manufactured with the sorghum-A. oryzae malt contained about $96 \%$ lower content of VDK. This important difference in volatile 
compounds needs to be further researched especially in terms of beer stability and sensory analysis. According to the EBC scale, the sorghum beers are classified as pale whereas the slightly darker yellowish barley beer as Pilsner. The final beer color is influenced by the type of malt, color of brewing adjuncts, concentration and type of hops and $\mathrm{pH}$ (Esslinger 2009). The almost twice as high color score observed in the barley beer is attributed to the utilization of a malt rich in glumes that contain phenolic compounds that lixiviated into the wort and the production of Maillard type of compounds during boiling (Granato et al. 2011). It is worth mentioning that both sorghum beers were produced from naked caryopses of white sorghum that do not contain tannins and were low in phenolic compounds (Serna-Saldivar and EspinosaRamirez, 2018). Differences of ethyl hexanoate, hydrogen sulfide, methanethiol and VKD compounds could have also affected beer color. According to Dack et al. (2017), Maillard reaction products inhibit the synthesis of esters due to possible suppression of enzymes and/or gene expression linked to ester synthesis. The impact of FAN on formation of flavor and aroma compounds during fermentation has been previously studied. Initial wort FAN content and the amino acid and ammonium ion equilibrium in the medium impact the formation of esters, aldehydes, VKD, superior alcohols and acids, as well as sulfur compounds. Even small differences in wort composition can exert significant effect on the flavor of the resulting beer (Hill and Stewart 2019). According to Taylor et al. (2013), and Kobayashi et al. (2008), there is some indication that the differences in the free amino acid profile of sorghum malt worts compared with barley malt worts could influence beer flavor by affecting yeast metabolism. Sorghum malt worts were found to contain low levels of branched chain valine. The amino acid profiles of barley and sorghum differed because the first commonly contained $2.2 \mathrm{~g}$ of methionine and $1.8 \mathrm{~g}$ of cysteine per $100 \mathrm{~g}$ of protein whereas the second $1 \mathrm{~g}$ of methionine and $1.6 \mathrm{~g}$ of cysteine per $100 \mathrm{~g}$ of protein (Serna-Saldivar 2010).

\section{Conclusion}

Simultaneous solid-state fermentation with $1 \%$ A. oryzae of sorghum undergoing germination produced a malt that increased wort and beer yield (12\% more ethanol) compared to the regular sorghum malt. Beers produced with the $A$. oryzae-sorghum malt had similar yield and alcohol content compared to the barley malt beer but differed in color, key volatile and aromatic compounds. Further investigations into changes in protein solubility, amino acids' profile changes during solid-state fermentation of sorghum malt with A. oryzae and it relation with changes in superior alcohols and other flavor beer components is in need.

\section{Abbreviations}

A. oryzae: Aspergillus oryzae; AACC: American Association of Cereal Chemists; ABSC: American Society of Brewing Chemists; AOAC: Association of Official Analytical Collaboration; ATCC: American Type Culture Collection; EBC: European Brewing Convention; FAN: Free amino nitrogen; FAO: Food Agriculture Organization; HPLC: High-performance liquid chromatograph; NIR: Near infrared spectroscopy; US: United States; VKD: Vicinal diketones; WHO: World Health Organization.

\section{Acknowledgements \\ The authors would like to thank Cervecería Cuahutemoc Moctezuma.}

\section{Authors' contributions}

SOSS conceptualize the idea, designed the work. MRF and ARGA performed experiments. All authors discussed the results. MRF, SOSS, and EPC cowrote the paper. All authors read and approved the final manuscript.

\section{Funding}

This research was supported by the research group of Nutriomics and Emerging Technologies from Tecnologico de Monterrey.

\section{Availability of data and materials}

The data that support the findings of this study are available from the corresponding author Sergio O. Serna-Saldivar (SOSS), upon reasonable request.

Ethics approval and consent to participate

This article does not contain any studies with human participants or animals.

\section{Consent for publication}

I, Sergio O. Serna-Saldivar (SOSS), the corresponding author, hereby declare that it is my study and I developed the manuscript titled "Use of Aspergillus oryzae during sorghum malting to enhance yield and quality of gluten-free lager beers".

\section{Competing interests}

The authors declare that they have no competing interests.

Received: 4 May 2020 Accepted: 7 July 2020

Published online: 15 July 2020

\section{References}

AACC (2000) Approved methods of the AACC, 10th edn. American Association of Cereal Chemists, St. Paul

AOAC (1980) Official methods of the association of official analytical collaboration. AOAC, Washington

ASBC (1994) Methods of analysis method beer-44 dimethyl sulfide by chemiluminescence detection. American Society of Brewing Chemists, St. Paul

Barbesgaard P, Heldt-Hansen HP, Diderichsen B (1992) On the safety of Aspergillus oryzae: a review. Appl Microbiol Biotechnol 36:569-572. https://doi. org/10.1007/BF00183230

Barredo-Moguel LH, Rojas de Gante C, Serna-Saldivar SO (2001) Alpha amino nitrogen and fusel alcohols of sorghum worts fermented into lager beer. J Inst Brew 107:367-372

Bendiak D (1997) Determination of percent yeast solids by a spin-down method. J Am Brew Soc 55(4):176-178. https://doi.org/10.1094/ASBCJ $-55-0176$

Bogdan P, Kordialik-Bogacka E (2017) Alternatives to malt in brewing. Trends Food Sci Technol 65:1-9. https://doi.org/10.1016/j.tifs.2017.05.001

Boulton C, Quain D (2001) Brewing yeast and fermentation. Blackwell Science, Malden

Briggs DE, Boulton CA, Brookes PA, Stevens R (2004) Brewing science and practice. CRC Press, Boca Raton

Carlsen M, Nielsen J (2001) Influence of carbon source on a-amylase production by Aspergillus oryzae. Appl Microbiol Biotechnol 57:346-349. https:// doi.org/10.1007/s002530100772

Cason DT, Reid GC, Gatner EMS (1987) On the differing rates of fructose and glucose utilisation in Saccharomyces cerevisiae. J Int Brew 93:23-25. https ://doi.org/10.1002/j.2050-0416.1987.tb04470.x 
Cortes-Ceballos E, Nava-Valdez Y, Pérez-Carrillo E, Serna-Saldívar SO (2015) Effect of the use of thermoplastic extruded corn or sorghum starches on the brewing performance of lager beers. J Am Soc Brew Chem 73(4):318-322. https://doi.org/10.1094/ASBCJ-2015-1002-01

Dack RE, Black GW, Koutsides G, Usher SJ (2017) The effect of Maillard reaction products and yeast strain on the synthesis of key higher alcohols and esters in beer fermentation. Food Chem 232:595-601. https://doi. org/10.1016/j.foodchem.2017.04.043

EBC (2008) Analtytica European brewing convention. Fachverlag Hans Carl Gmbh, Nuremberg

Espinosa-Ramírez J, Pérez-Carrillo E, Serna-Saldívar SO (2013a) Production of lager beers from different types of sorghum malts and adjuncts supplemented with $\beta$-amylase or amyloglucosidase. J Am Soc Brew Chem 71:208-213. https://doi.org/10.1094/ASBCJ-2013-0914-01

Espinosa-Ramírez J, Pérez-Carrillo E, Serna-Saldívar SO (2013b) Production of brewing worts from different types of sorghum malts and adjuncts supplemented with $\beta$-amylase or amyloglucosidase. J Am Soc Brew Chem 71:49-56. https://doi.org/10.1094/ASBCJ-2013-0125-01

Espinosa-Ramírez J, Pérez-Carrillo E, Serna-Saldívar SO (2014) Maltose and glucose during fermentation of barley and sorghum lager beers as affected by $\beta$-amylase or amyloglucosidase addition. J Cereal Sci 60:602-609. https://doi.org/10.1016/j.jcs.2014.07.008

Esslinger HM (2009) Handbook of brewing: processes, technology, markets. Wiley VCH, Weinheim

FAO, WHO (1988) Joint FAO/WHO expert committee on food additives. WHO Tech Rep Ser 759:16-17

Food Agriculture Organization (2019) Statistical database. Rome. http://faost at.fao.org. Accessed 15 Feb 2019

Gialleli A-I, Ganatsios V, Terpou A, Kanalleki M, Bekatorou A, Koutinas AA, Dimitrellou D (2017) Technological development of brewing in domestic refrigerator using freeze-dried raw materials. Food Technol Biotechnol 55:325-332. https://doi.org/10.17113/ftb.55.03.17.4907

Granato D, Branco GF, Faria JAF, Cruz AG (2011) Characterization of Brazilian lager and brown ale beers based on color, phenolic compounds, and antioxidant activity using chemometrics. J Sci Food Agric 91:563-571. https://doi.org/10.1002/jsfa.4222

Gupta M, Abu-Ghannam N, Gallaghar E (2010) Barley for brewing: characteristic changes during malting, brewing and applications of its by-products. Comp Rev Food Sci Food Saf 9:318-329. https://doi.org/10.111 1/j.1541-4337.2010.00112.x

Heredia-Olea E, Cortés-Ceballos E, Serna-Saldívar SO (2017) Malting sorghum with Aspergillus oryzae enhances gluten-free wort yield and extract. J Am Soc Brew Chem 75:116-121. https://doi.org/10.1094/ASBCJ $-2017-2481-01$

Hill AE, Stewart GG (2019) Free amino nitrogen in brewing. Fermentation 5(1):22. https://doi.org/10.3390/fermentation5010022
Kammoun R, Naili B, Bejar S (2008) Application of statistical design to the optimization of parameters and culture medium for a-amylases productiono of Aspergillus oryzae CBS 819.72 grown on gruel (wheat grinding by-product). Bioresource Technology. 99(13):5602-5609

Kobayashi T, Abe K, Asai K, Gomi K, Juvvdi PR, Kato M, Kitamoto K, Takeuchi M, Machida M (2007) Genomics of Aspergillus oryzae. Biosci Biotechnol Biochem 7:649-670. https://doi.org/10.1271/bbb.60550

Kobayashi M, Shimizu H, Shioya S (2008) Beer volatile compounds and their application to low-malt beer fermentation. J Biosci Bioeng 106:317-323. https://doi.org/10.1263/jbb.106.317

Machida M, Asai K, Sano M, Tanaka T, Kumagai T, Terai G, Kusumot K-I, Arima T, Akita O, Kashiwagi Y, Abe K, Gomi K, Horiuchi H (2005) Genome sequencing and analysis of Aspergillus oryzae. Nat Lett 438:1157-1161. https://doi. org/10.1038/nature04300

Odibo FJC, Nwankwo LN, Agu RC (2002) Production of malt extract and beer from Nigerian sorghum varieties. Process Biochem 37:851-855. https:// doi.org/10.1016/S0032-9592(01)00286-2

Pires EJ, Teixeira JA, Brányik T, Vicente AA (2014) Yeast: the soul of beer's aroma-a review of flavour-active esters and higher alcohols produced by the brewing yeast. Appl Microbiol Biotechnol 98:1937-1949. https:// doi.org/10.1007/s00253-013-5470-0

Serna-Saldivar SO (2010) Cereal grains properties, processing and nutritional attributes. CRC Press, Boca Raton

Serna-Saldivar SO (2012) Cereal grains: laboratory reference and procedures manual. CRC Press, Taylor \& Francis Group, Boca Raton

Serna-Saldivar SO, Espinosa-Ramirez J (2018) Grain structure and grain chemical composition. Chapter 5 In: Sorghum \& millets: chemistry, technology and nutritional attributes. In: Taylor JRN, Duodu KG (editors). 2nd ed. Elsevier (Woodhead Publishing), AACC-International, pp 85-129

Serna-Saldivar SO, Rubio-Flores M (2016) Role of intrinsic and supplemented enzymes in brewing and beer properties. Chapter 15 In: Microbial enzyme technology and food applications. Ray RC, Rosell CM, (eds). CRC Press Taylor \& Francis Group, Boca Raton, pp 273-298

Taylor JR, Dlamini BC, Kruger J (2013) 125th Anniversary Review: The science of the tropical cereals sorghum, maize and rice in relation to lager beer brewing. J Inst Brew 119:1-14. https://doi.org/10.1002/jib.68

Zastrow C, Mattos M, Hollatz C, Stambuk BU (2000) Maltotriose metabolism by Saccharomyces cerevisiae. Biotechnol Lett 22:455-459. https://doi. org/10.1023/A:1005691031880

\section{Publisher's Note}

Springer Nature remains neutral with regard to jurisdictional claims in published maps and institutional affiliations.

\section{Submit your manuscript to a SpringerOpen ${ }^{\circ}$ journal and benefit from:}

- Convenient online submission

- Rigorous peer review

- Open access: articles freely available online

- High visibility within the field

- Retaining the copyright to your article

Submit your next manuscript at springeropen.com 